\title{
Antioxidant Properties of Experimental Wholegrain Pastas Made With Different Cereals
}

\author{
Alessandra Durazzo ${ }^{1}$, Valeria Turfani ${ }^{1}$, Elena Azzini ${ }^{1}$, Giuseppe Maiani ${ }^{1} \&$ Marina Carcea ${ }^{1}$ \\ ${ }^{1}$ Agricultural Research Council-Food and Nutrition Research Centre (CRA-NUT), Via Ardeatina 546, 00178, \\ Rome, Italy \\ Correspondence: Alessandra Durazzo, Agricultural Research Council-Food and Nutrition Research Centre \\ (CRA-NUT), Via Ardeatina 546, 00178, Rome, Italy. Tel: 39-065-149-4651. E-mail: \\ alessandra.durazzo@entecra.it
}

Received: June 10, 2013 Accepted: December 10, 2013 Online Published: April 10, 2014

doi:10.5539/jfr.v3n4p33 URL: http://dx.doi.org/10.5539/jfr.v3n4p33

\begin{abstract}
Pasta represents an identifying ingredient of traditional healthy dishes, in particular in Mediterranean areas. Traditional pasta is made with durum wheat semolina only. However, pasta manufactured with different cereals has become available on the market and its consumption is rapidly increasing.

Five experimental dry pastas, manufactured with the same process by adding $60 \%$ wholegrain flours of different cereals (wheat, oat, rye, barley and rice) to the same durum wheat semolina, were supplied by Pavan s.p.a. (Galliera Veneta, PD, Italy).

For each product, aqueous-organic extracts and their residues were studied. Their antioxidant properties were evaluated by FRAP (Ferric Reducing Antioxidant Power) assay and Total Polyphenols Content (TPC) was determined by the Folin Ciocalteau method.

For cooked experimental wholegrain pastas made with different cereals, FRAP values ranged from $3.26 \pm 0.08$ $\mu \mathrm{mol} / \mathrm{g}$ d.w. to $19.52 \pm 1.28 \mu \mathrm{mol} / \mathrm{g}$ d.w. in aqueous-organic extracts and from $17.91 \pm 2.83 \mu \mathrm{mol} / \mathrm{g}$ d.w. to $87.83 \pm 5.06 \mu \mathrm{mol} / \mathrm{g}$ d.w. in residues. In both raw and cooked products the lowest FRAP values were found for semolina $/ 60 \%$ whole rice pasta.
\end{abstract}

The barley pasta has interesting antioxidant properties and this result was matched by the TPC one.

\section{Practical Application}

The interest in more nutritious and potentially functional foods has prompted the cereal industry towards new formulations of wholegrain products. The functional properties of minor cereals have been poorly investigated. Our results show that wholegrain pastas made with different cereals are rich in antioxidants, in particular whole barley based pasta, providing a scientific basis for the development of grain based functional foods.

Then the study of free and bond bioactive compounds could be crucial to describe the potential of grains, with the aim of better understanding potential health benefits of wholegrain based food consumption.

Keywords: cereals, pasta, antioxidants, aqueous-organic extract, residue

\section{Introduction}

Pasta represents an identifying ingredient of traditional healthy dishes, in particular in Mediterranean areas (Krishnan \& Prabhasankar, 2012).

A lot of scientific evidences have recognized the pasta's healthy place in the diet for its nutritional and beneficial properties (Augustin et al., 2001; Wolever et al., 2008).

Foods based on wholegrain cereals have a key role in health and well-being (Slavin, 2004; Okarter \& Liu, 2010). Several researches suggest that eating wholegrain products as a part of a healthy diet could be useful to reduce the risk of several diseases (Venn \& Mann, 2004; Lockheart et al., 2007; Munter, Hu, Spiegelman, Franz, \& Dam, 2007; Venn \& Green, 2007; Poutanen et al., 2008; Enright \& Slavin, 2010; Harris \& Kris-Etherton, 2010; Gil, Ortega, \& Maldonado, 2011; Borneo \& Leon, 2012).

Wholegrain cereals have a unique phytochemical composition: vitamins and minerals, unsaturated fatty acids, 
tocotrienols, tocopherols, insoluble and soluble fiber, phytosterols, stanols, sphingolipids, phytates, lignans, and antioxidants like phenolics (Adom \& Liu, 2002; Marquat, Slavin, \& Fulcher, 2002; Jensen et al., 2004; Adom, Sorrells, \& Liu, 2003; Adom, Sorrells, \& Liu, 2005; Liu, 2007; Okarter, Liu, Sorrells, \& Liu, 2010).

Cereals represent a potentially rich source of natural antioxidants (Manach, Scalbert, Morand, Remesy, \& Jimenez, 2004). Polyphenols in cereals are present as easily extractable compounds (free) and as less extractable types (bound) (Bravo, Manas, \& Saura-Calixto, 1993; Bravo, Albia, \& Saura-Calixto, 1994). The content of antioxidants in cereals have been underestimated. Grains contain more antioxidants than previously thought due to a relatively high amount of bound components (Adom \& Liu, 2002; Perez-Jimenez \& Saura-Calixto, 2005). Chemical extraction is affected by several factors such as type of solvents, extraction time, and temperature as well as by the chemical compositions and physical characteristics of the sample. Previous investigations have studied and determined phenol content using ethanol, methanol and acetone to extract soluble phenols (Velioglu, Mazza, Gao, \& Oomah, 1998; Zielinski \& Kozlowska, 2000; Yu, Haley, Perret, \& Harris, 2002a; Yu, Perret, Davy, Wilson, \& Melby, 2002b; Adom, Sorrells, \& Liu, 2003; Liyana-Pathirana \& Shahidi, 2006). Several authors have used acidic methanol/water as extraction solvent to improve extraction (Iqbal, Bhanger, \& Anwar, 2005; Awika, Rooney, \& Waniska, 2005).

Recent investigations have used an alkaline hydrolysis, acid hydrolysis, or enzymatic digestion (Pérez-Jiménez \& Saura-Calixto, 2005; Nagah \& Seal, 2005; Moore et al., 2005).

In this work aqueous-organic extracts (extractable polyphenols) and potentially bioactive polyphenols that remain in the residues (non-extractable polyphenols) of experimental wholegrain pastas made with different cereals were investigated in the raw and in the cooked state.

\section{Materials and Methods}

\subsection{Samples and Sample Preparation}

Five experimental dry pastas, manufactured with the same process by adding $60 \%$ wholegrain flours of different cereals (wheat, oat, rye, barley and rice) to the same durum wheat semolina, were supplied by Pavan s.p.a. (Galliera Veneta, PD, Italy).

Preliminary tests were carried out by Pavan for determining the maximum percentage of non-semolina flour to use in the manufacturing of acceptable pasta as well as the best shape. All Pavan's pastas had the same shape (macaroni), average thickness (between 1.14 and $1.22 \mathrm{~mm}$ ), optimum cooking time (between 8 and $9 \mathrm{~min}$ ).

Raw pasta products were ground in a refrigerated mill (Janke and Kunkel, Ika Labortechnik, Germany) and the flours were sieved until a granulometry of $0.5 \mathrm{~mm}$.

Wholegrain pastas were cooked following the manufacturer's directions in unsalted and distilled water, frozen, lyophilized and milled.

\subsection{Chemicals and Reagents}

All reagents and solvents used were of analytical or HPLC grade; all chemicals were purchased from Sigma-Aldrich Srl (Milan, Italy), Fluka Chemicals (Madrid, Spain), Carlo Erba (Milan, Italy). Double-distilled water (Millipore, Milan, Italy) was used throughout the study.

\subsection{Sample Extraction}

Extractable polyphenols (aqueous-organic extracts) and non-extractable polyphenols (residues) were extracted, isolated and studied as described by Durazzo et al. (2012). In particular in residues, among non-extractable polyphenols, hydrolysable polyphenols (comprising hydrolysable tannins, phenolic acids and hydroxycinnamic acids that are released from the food matrix by strong acidic hydrolysis) were determined. The antioxidant properties and the Total Polyphenol Content (TPC) were determined in both aqueous-organic extracts and their residues.

\subsection{Determination of Total Polyphenol Content (TPC)}

The Total Polyphenol Content (TPC) was determined using the Folin-Ciocalteau method previously described by Singleton, Orthofer, and Lamuela-Raventos, 1999. Briefly, the appropriate dilutions of extracts were oxidized with Folin-Ciocalteau reagent, and the reaction mixture was neutralized with sodium carbonate. The absorbance of the resulting blue color was measured at $760 \mathrm{~nm}$ against a blank after $2 \mathrm{~h}$ of reaction at room temperature. Gallic acid was used as the standard.

\subsection{Evaluation of Antioxidant Properties}

Antioxidant properties have been determined by the FRAP (Ferric Reducing Antioxidant Power) assay. The 
method was performed as described by Benzie and Strain (1996) and Pulido, Bravo, and Saura-Calixto, (2000) using a Tecan Sunrise ${ }^{\circledR}$ plate reader spectrophotometer. The method is based on the reduction of the yellow $\mathrm{Fe}^{3+}$-TPTZ (2,4,6-tripyridyl-s-triazine) complex to the blue ferrous complex at low $\mathrm{pH}$. The absorbance was recorded at $595 \mathrm{~nm}$ after $30 \mathrm{~min}$ incubation at $37^{\circ} \mathrm{C}$.

\subsection{Statistical Analysis}

The data presented are the means of three separate extractions and determinations. Results were expressed as mean \pm standard deviation (SD). Differences among groups using a significance level of $\mathrm{P}<0.05$ were performed by one-way analysis of variance (ANOVA) using the Statistica for Windows statistical package (release 4.5; StatSoft Inc., Vigonza PD, Italy). Significant differences between raw and cooked products have been evaluated by Student $t$ test.

\section{Results}

Figures 1A-1B show TPC values (mg/100g d.w.) and FRAP values ( $\mu \mathrm{mol} / \mathrm{g}$ d.w.) in aqueous-organic extracts and residues of raw, experimental, wholegrain pastas made with different cereals.

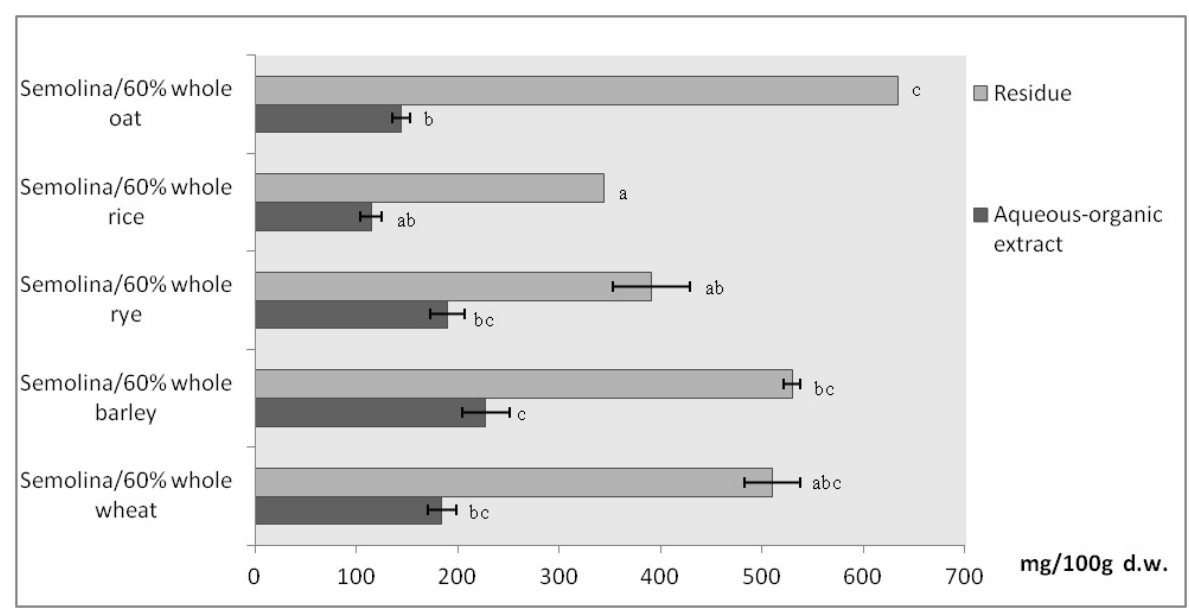

Figure 1A. TPC values in raw, experimental, wholegrain pastas made with different cereals *

*mean \pm S.D.; Anova, Tukey HSD Test; for each fraction, means followed by different letters are significantly different $(\mathrm{P}<0.05)$.

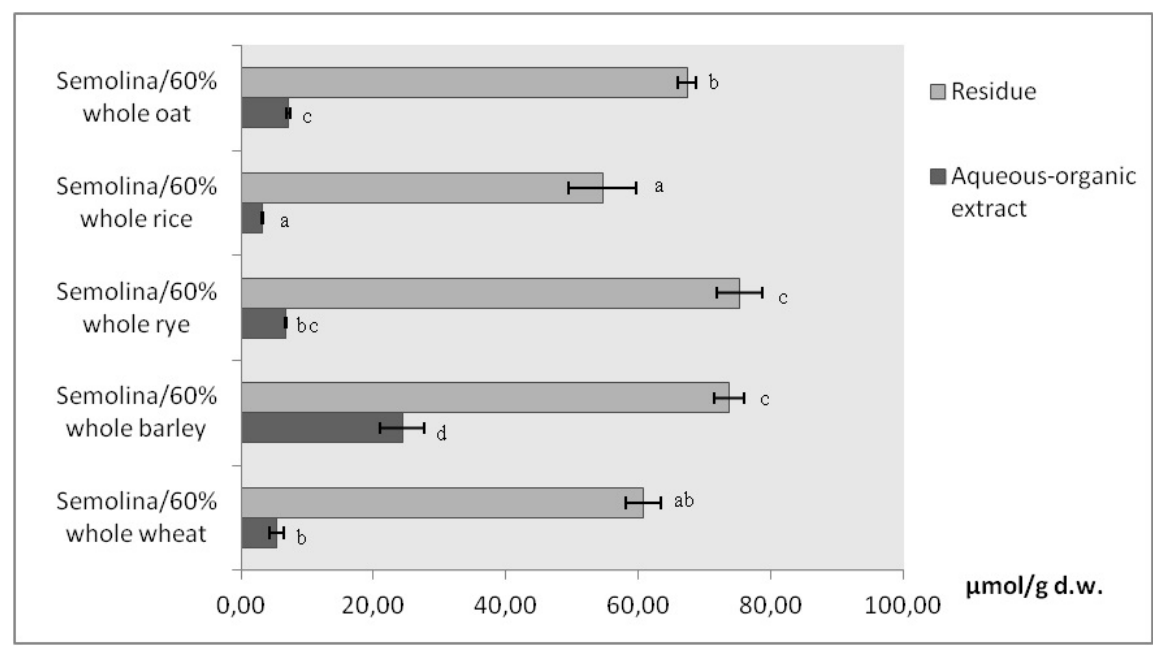

Figure 1B. FRAP values in raw, experimental, wholegrain pastas made with different cereals *

*mean \pm S.D.; Anova, Tukey HSD Test; for each fraction, means followed by different letters are significantly different $(\mathrm{P}<0.05)$. 
TPC (mg/100g d.w.) varies within the range 114.28-227.34 mg/100g d.w. in aqueous-organic extracts and within the range 343.55-634.30 mg/100g d.w. in residues (Figure 1A), whereas FRAP values ranged from $3.19 \pm 0.09$ $\mu \mathrm{mol} / \mathrm{g}$ d.w. to $24.4 \pm 3.32 \mu \mathrm{mol} / \mathrm{g}$ d.w. in aqueous-organic extracts and from $54.62 \pm 5.14 \mu \mathrm{mol} / \mathrm{g}$ d.w. to 75.35 $\pm 3.44 \mu \mathrm{mol} / \mathrm{g}$ d.w. in residues (Figure 1B). The semolina/60\% whole rice pasta had the lowest FRAP value for both aqueous-organic extract and residue, while the semolina $/ 60 \%$ whole barley pasta reached the highest value for aqueous-organic extract and barley and rye based pastas for residue.

The barley pasta has interesting antioxidant properties and this result was matched by the TPC one. Several authors have demonstrated that pearled barley fractions are suitable for making functional pastas (Marconi, Graziano, \& Cubadda, 2000; Verardo, Gomez-Caravaca, Messia, Marconi, \& Caboni, 2011). Verardo, Gomez-Caravaca, Messia, Marconi, and Caboni (2011) have obtained spaghetti enriched in bioactive compounds using barley coarse fraction as an ingredient.

In addition it is interesting to underline that in all selected products the hydrolysable polyphenols represent a quantitatively important fraction of polyphenols: the hydrolysable polyphenols content is major than the extractable polyphenols one in all samples.

In particular in raw products the hydrolysable polyphenols contribution to antioxidant properties ranged from $75 \%$ in whole barley based pasta to $94 \%$ in whole rice based pasta, whereas in cooked pasta ranged from $81 \%$ to $92 \%$.

In Figure 2A-2B TPC values (mg/100g d.w.) and Frap values ( $\mu \mathrm{mol} / \mathrm{g}$ d.w.) in aqueous-organic extracts and residues of cooked, experimental, wholegrain pastas made with different cereals were reported. Anese, Nicoli, Massimi, and Lerici (1999) have shown that temperature, time and moisture conditions of the drying process have a significant impact of antioxidant properties of pasta.

Slavin (2003) has observed that bioactive compounds produced during processing contribute to the antioxidant power of the grain products. Several researches have shown that non-enzymatic browning reactions such as the Maillard reaction could generate antioxidant molecules (Manzocco, Calligaris, Mastrocola, Nicoli, \& Lerici, 2001; Amarowicz, 2009).

For cooked experimental wholegrain pastas made with different cereals, TPC varies within the range $128.84-226.38 \mathrm{mg} / 100 \mathrm{~g}$ d.w. in aqueous-organic extracts and within the range $701.36-1041.10 \mathrm{mg} / 100 \mathrm{~g}$ d.w. in residues (Figure 2A).

FRAP values ranged from $3.26 \pm 0.08 \mu \mathrm{mol} / \mathrm{g}$ d.w. to $19.52 \pm 1.28 \mu \mathrm{mol} / \mathrm{g}$ d.w. in aqueous-organic extracts and from $17.91 \pm 2.83 \mu \mathrm{mol} / \mathrm{g}$ d.w. to $87.83 \pm 5.06 \mu \mathrm{mol} / \mathrm{g}$ d.w. in residues (Figure 2B). In both raw and cooked products the lowest FRAP values were found for semolina $/ 60 \%$ whole rice pasta. In addition, in rice based pasta, after cooking, a decrease of FRAP value has been reported in residue $(\mathrm{P}<0.001)$, even if significant increases in TPC values have been reported in aqueous-organic extract $(\mathrm{P}<0.01)$ and in residue $(\mathrm{P}<0.01)$.

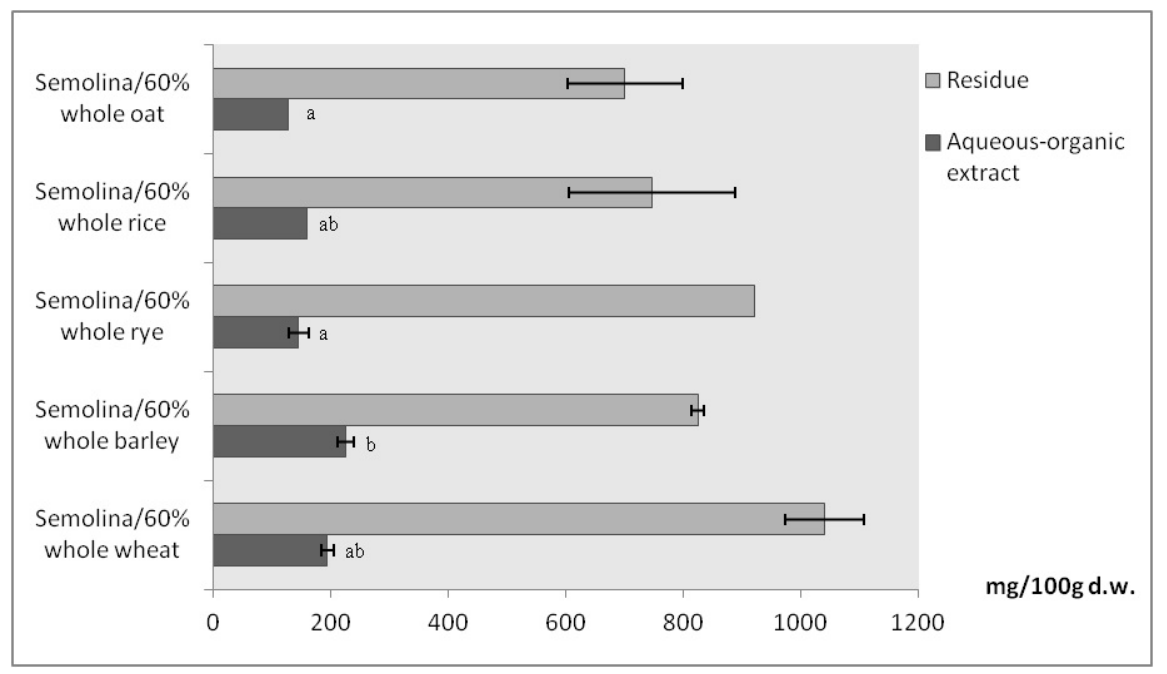

Figure 2A. TPC values in cooked, experimental, wholegrain pastas made with different cereals *

*mean \pm S.D.; Anova, Tukey HSD Test; for each fraction, means followed by different letters are significantly different $(\mathrm{P}<0.05)$. 


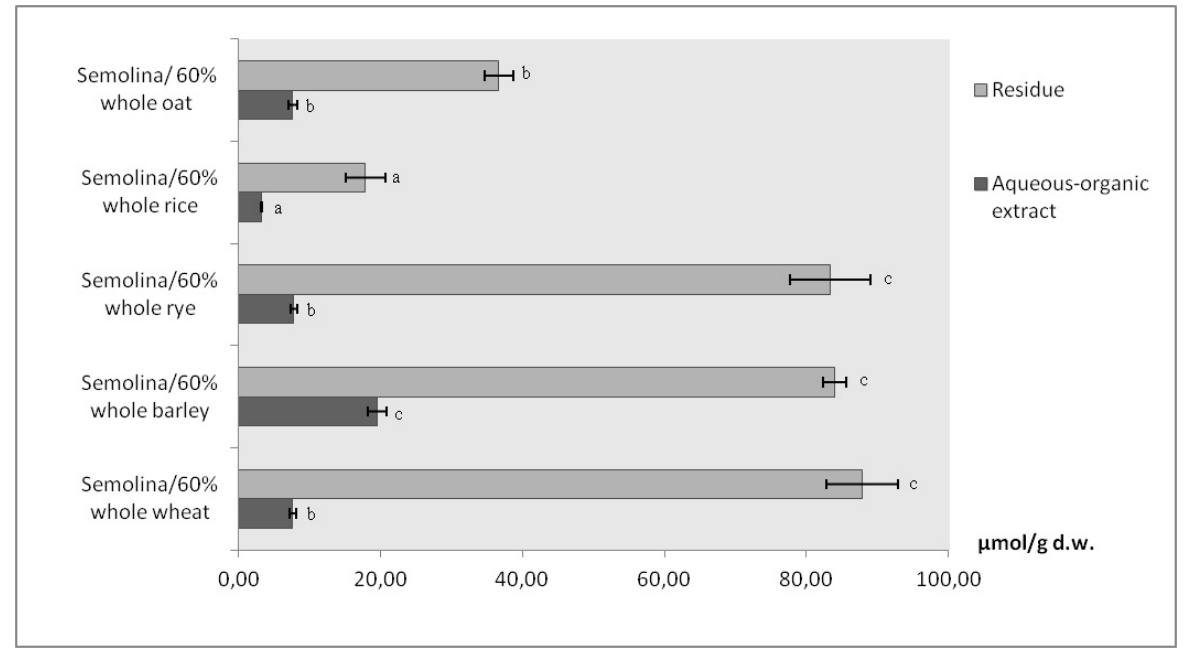

Figure 2B. FRAP values in cooked, experimental, wholegrain pastas made with different cereals *

*mean \pm S.D.; Anova, Tukey HSD Test; for each fraction, means followed by different letters are significantly different $(\mathrm{P}<0.05)$

Comparing raw and cooked products, a significant increase in FRAP values of aqueous-organic extract $(\mathrm{P}<0.05)$ and residue $(\mathrm{P}<0.01)$ as well as in TPC of residue $(\mathrm{P}<0.001)$ has been reported for semolina $/ 60 \%$ whole wheat pasta. Fares, Platani, Baiano, and Menga (2010) have shown that boiling water improve the extraction of bound phenolics from the food matrix in wheat pasta enriched with debranning fractions of wheat. On the contrary, Hirawan, Ser, Arntfield, and Beta (2010) have found that the total phenols content reduce by $40 \%$ in both regular and whole wheat brands after cooking.

From our results, after cooking, also for barley based pasta significant increases in FRAP value $(\mathrm{P}<0.01)$ and in TPC $(\mathrm{P}<0.001)$ were observed in residue.

For semolina/ $60 \%$ whole oat pasta a different trend was reported: significant decreases in FRAP value $(\mathrm{P}<0.001)$ of residue and in TPC $(\mathrm{P}<0.05)$ of aqueous-organic extract were observed.

Then cooked rye based pasta has higher FRAP value $(\mathrm{P}<0.05)$ and lower TPC $(\mathrm{P}<0.05)$ in aqueous-organic extract than raw product, whereas in residue after cooking an increase in TPC $(\mathrm{P}<0.001)$ has been reported.

\section{Conclusions}

In this research our results have shown the antioxidant characteristics of wholegrain pastas made with different cereals, barley added pasta in particular. Our results confirm that the effect of cooking depends on the nature of food matrix. These results can provide a scientific basis for the development of wholegrain based functional foods.

\section{Acknowledgements}

The authors are grateful to Pavan s.p.a for providing the samples. The authors thank the secretarial assistance of Mr. Francesco Martiri.

\section{Reference}

Adom, K., \& Liu, R. (2002). Antioxidant activity of grains. Journal of Agricultural and Food Chemistry, 50, 6182-6187. http://dx.doi.org/10.1021/jf0205099

Adom, K. K., Sorrells, M. E., \& Liu, R. H. (2003). Phytochemical profiles and antioxidant activity of wheat varieties. Journal of Agricultural and Food Chemistry, 51, 7825-7834. http://dx.doi.org/10.1021/jf0304041

Adom, K. K., Sorrells, M. E., \& Liu, R. H. (2005). Phytochemicals and antioxidant activity of milled fractions of different wheat varieties. Journal of Agricultural and Food Chemistry, 53, 2297-2306. http://dx.doi.org/10.1021/jf048456d

Amarowicz, R. (2009). Antioxidant activity of Maillard reaction products. European Journal of Lipid Science and Technology, 111, 109-111. http://dx.doi.org/10.1002/ejlt.200900011 
Anese, M., Nicoli, M. C., Massimi, R., \& Lerici, C. R. (1999). Effects of drying processing on the Maillard reaction in pasta. Food Research International, 32, 193-199. http://dx.doi.org/10.1016/S0963-9969(99)00076-9

Augustin, L. S. A., Dal Maso, L., La Vecchia, C., Parpinel, M., Negri, E., Vaccarella, S., ... Franceschi, S. (2001). Dietary glycemic index and glycemic load, and breast cancer risk: a case-control study. Annals of Oncology, 12, 1533-1538. http://dx.doi.org/10.1023/A:1013176129380

Awika, S. M., Rooney, L. W., \& Waniska, R. D. (2005). Anthocyanins from black sorghum and their antioxidant properties. Food Chemistry, 90, 293-301. http://dx.doi.org/10.1016/j.foodchem.2004.03.058

Benzie, I. F. F., \& Strain, J. J. (1996). The ferric reducing ability of plasma (FRAP) as a measure of "antioxidant power": the assay. Analytical Biochemistry, 239, 70-76. http://dx.doi.org/10.1006/abio.1996.0292

Borneo, R., \& Leon, A. E. (2012). Whole grain cereals: functional components and health benefits. Food \& Function, 3(2), 110-119. http://dx.doi.org/10.1039/c1fo10165j

Bravo, L., Manas, E., \& Saura-Calixto, F. (1993). Dietary non-extractable condensed tannins as indigestible compounds; effects on faecal weight, an protein and fat excretion. Journal of the Science of Food and Agriculture, 63, 63-68. http://dx.doi.org/10.1002/jsfa.2740630111

Bravo, L., Albia, R., \& Saura-Calixto, F. (1994). Polyphenols dietary fiber associated compounds. Comparative study on in vivo and in vitro properties. Journal of Agriculture and Food Chemistry, 42, 1481-1487. http://dx.doi.org/10.1021/jf00043a017

Durazzo, A., Turfani, V., Azzini, E., Maiani, G., \& Carcea M. (2013). Phenols, lignans and antioxidant properties of legume and sweet chestnut flours. Food Chemistry, 140, 666-671. http://dx.doi.org/10.1016/j.foodchem.2012.09.062

Enright, L., \& Slavin, J. (2010). No effect of 14 day consumption of whole grain diet compared to refined grain diet on antioxidant measures in healthy, young subjects: a pilot study. Nutrition Journal, 9, 12-19. http://dx.doi.org/10.1186/1475-2891-9-12

Fares, C., Platani, C., Baiano, A., \& Menga, V. (2010). Effect of processing and cooking on phenolic acid profile and antioxidant capacity of durum wheat pasta enriched with debranning fractions of wheat. Food Chemistry, 119, 1023-1029. http://dx.doi.org/10.1016/j.foodchem.2009.08.006

Gil, A., Ortega, R. M., \& Maldonado, J. (2011). Wholegrain cereals and bread: a duet of the Mediterranean diet for the prevention of chronic diseases. Public Health Nutrition, 14, 2316-2322. http://dx.doi.org/10.1017/S1368980011002576

Harris, K. A., \& Kris-Etherton, P. M. (2010). Effects of whole grains on coronary heart disease risk. Current Atherosclerosis Reports, 12, 368-376. http://dx.doi.org/10.1007/s11883-010-0136-1

Hirawan, R., Ser, W. Y., Arntfield, S. D., \& Beta, T. (2010). Antioxidant properties of commercial, regular- and whole-wheat spaghetti. Food Chemistry, 119, 258-264. http://dx.doi.org/10.1016/j.foodchem.2009.06.022

Iqbal, S., Bhanger, M. I., \& Anwar, F. (2005). Antioxidant properties and components of some commercially available varieties of rice bran in Pakistan. Food Chemistry, 93, 265-272. http://dx.doi.org/10.1016/j.foodchem.2004.09.024

Jensen, M. K., Koh-Bahnarjee, P., Hu, F. B., Franz, M., Sampson, L., Gronbek, M., \& Rimm, E. B. (2004). Intakes of whole grains, bran, and germ and the risk of coronary heart disease in men. American Journal of Clinical Nutrition, 80, 1492-1499.

Krishnan, M., \& Prabhasankar, P. (2012). Health based pasta: redefining the concept of the next generation convenience food. Critical Reviews in Food Science and Nutrition, 52, 9-20. http://dx.doi.org/10.1080/10408398.2010.486909

Lockheart, M. S, Steffen, L. M., Rebnord, H. M., Fimreite, R. L., Ringastas, J., Thelle, D. S., ... Jacobs, D. R. (2007). Dietary patterns, food groups and myocardial infarction: a case-control study. British Journal of Nutrition, 98, 380-387. http://dx.doi.org/10.1017/S0007114507701654

Liu, R. H. (2007). Whole grain phytochemicals and health. Journal of Cereal Science, 46, 207-219. http://dx.doi.org/10.1016/j.jcs.2007.06.010

Liyana-Pathirana, C. M., \& Shahidi, F. (2006). Antioxidant properties of commercial soft and hard winter wheats (Triticum aestivum L.) and their milling fractions. Journal of the Science of Food and Agriculture, 86, 
477-485. http://dx.doi.org/10.1002/jsfa.2374

Manach, C., Scalbert, A., Morand, C., Remesy, C., \& Jimenez, L. (2004). Polyphenols: food sources and bioavailability. American Journal of Clinical Nutrition, 79(5), 727-747.

Manzocco, L., Calligaris, S., Mastrocola, D., Nicoli, M. C., \& Lerici, C. R. (2001). Review of non-enzymatic browning and antioxidant capacity in processed foods. Trends in Food Science and Technology, 11, 340-346. http://dx.doi.org/10.1016/S0924-2244(01)00014-0

Marconi, E., Graziano, M., \& Cubadda, R. (2000). Composition and utilization of barley pearling by-products for making functional pastas rich in dietary fiber and $\beta$-glucans. Cereal Chemistry, 77, 133-139. http://dx.doi.org/10.1094/CCHEM.2000.77.2.133

Marquat, L., Slavin, J. L., \& Fulcher, R. G. (2002). Whole-grain foods in health and disease. St Paul, MN: American Association of Cereal Chemists, Inc, 2002.

Moore, J., Hao, Z., Zhou, K., Luther, M., Costa, J., \& Yu, L. (2005). Carotenoid, tocopherol, phenolic acid, and antioxidant properties of Maryland-grown soft wheat. Journal of Agricultural and Food Chemistry, 53, 6649-6657. http://dx.doi.org/10.1021/jf050481b

Munter, J. S. L. D., Hu, F. B., Spiegelman, D., Franz, M., \& Dam, R. M. V. (2007). Whole grain, bran and germ intake and risk of type 2 diabetes: a prospective cohort study and systematic review. Plos Medicine, 4, e261. http://dx.doi.org/10.1371/journal.pmed.0040261

Nagah, A. M., \& Seal, C. J. (2005). In vitro procedure to predict apparent antioxidant release from wholegrain foods measured using three different analytical methods. Journal of the Science of Food and Agriculture, 85, 1177-1185. http://dx.doi.org/10.1002/jsfa.2106

Okarter, N., Liu, C. S., Sorrells, M. E., \& Liu, R. H. (2010). Phytochemical content and antioxidant activity of six diverse varieties of whole wheat. Food Chemistry, 119, 249-257. http://dx.doi.org/10.1016/j.foodchem.2009.06.021

Okarter, N., \& Liu, R. H. (2010). Health benefits of whole grain phytochemicals. Critical Reviews in Food Science and Nutrition, 50(3), 193-208. http://dx.doi.org/10.1080/10408390802248734

Perez-Jimenez, J., \& Saura-Calixto, F. (2005). Literature data may underestimate the actual antioxidant capacity of cereals. Journal of Agricultural and Food Chemistry, 53(12), 5036-5040. http://dx.doi.org/10.1021/jf050049u

Poutanen, K., Shepherd, R., Shewry, P. R., Delcour, J. A., Bjorck, I., \& Kamp, J. W. (2008). Beyond whole grain: the European HEALTHGRAIN project aims at healthier cereal foods. Cereal Foods World, 53, 32-35.

Pulido, R., Bravo, L., \& Saura-Calixto, F. (2000). Antioxidant activity of dietary polyphenols as determined by a modified ferric reducing/antioxidant power assay. Journal of Agricultural and Food Chemistry, 48, 3396-3402. http://dx.doi.org/10.1021/jf9913458

Singleton, V. L., Orthofer, R., \& Lamuela-Raventos, R. M. (1999). Analysis of total phenols and other oxidation substrates and antioxidants by means of Folin-Ciocalteau reagent. Methods in Enzymology, 299, 152-178. http://dx.doi.org/10.1016/S0076-6879(99)99017-1

Slavin, J. (2003). Why whole grains are protective: Biological mechanism. Proceedings of the Nutrition Society, 62, 129-134. http://dx.doi.org/10.1079/PNS2002221

Slavin, J. (2004). Whole grains and human health. Nutrition Research Reviews, 17, 99-110. http://dx.doi.org/10.1079/NRR200374

Velioglu, Y. S., Mazza, G., Gao, L., \& Oomah, B. D. (1998). Antioxidants activity and total phenolics in selected fruits, vegetables and grain products. Journal of Agricultural and Food Chemistry, 46, 4113-4117. http://dx.doi.org/10.1021/jf9801973

Venn, B. J., \& Green, T. J. (2007). Glycemic index and glycemic load: measurement issues and their effect on diet-disease relationships. European Journal of Clinical Nutrition, 61, S122-S131. http://dx.doi.org/10.1038/sj.ejen.1602942

Venn, B. J., \& Mann, J. I. (2004). Cereal grains, legumes and diabetes. European Journal of Clinical Nutrition, 58, 1443-61. http://dx.doi.org/10.1038/sj.ejcn.1601995

Verardo, V., Gomez-Caravaca, A. M., Messia, M. C., Marconi, E., \& Caboni, M. F. (2011). Development of functional spaghetti eriche in bioactive compounds using barley coarse fraction obtained by air 
classification. Journal of Agricultural and Food Chemistry, 59, 9127-9134. http://dx.doi.org/10.1021/jf202804v

Wolever, T. M. S., Gibbs, A. L., Mehling, C., Chiasson, J. L., Connelly, P. W., Josse, R. G., ... Ryan, A. (2008). The Canadian Trial of Carbohydrates in Diabetes (CCD), a 1-y controlled trial of low-glycemic-index dietary carbohydrate in type 2 diabetes: no effect on glycated hemoglobin but reduction in C-reactive protein. American Journal of Clinical Nutrition, 87(1), 114-125.

Yu, L., Haley, S., Perret, J., \& Harris, M. (2002a). Antioxidant properties of hard winter wheat extracts. Food Chemistry, 78, 457-461. http://dx.doi.org/10.1016/S0308-8146(02)00156-5

Yu, L., Perret, J., Davy, B., Wilson, J., \& Melby, C. (2002b). Antioxidant properties of cereal products. Journal of Food Science, 67(7), 2600-2603. http://dx.doi.org/10.1111/j.1365-2621.2002.tb08784.x

Zielinski, H., \& Kozlowka, H. (2000). Antioxidant activity and total phenolics in selected cereal grains and their different morphological fractions. Journal of Agricultural and Food Chemistry, 48, 2008-2016. http://dx.doi.org/10.1021/jf990619o

\section{Copyrights}

Copyright for this article is retained by the author(s), with first publication rights granted to the journal.

This is an open-access article distributed under the terms and conditions of the Creative Commons Attribution license (http://creativecommons.org/licenses/by/3.0/). 